Testosterone use in female mice does not impair fertilizability of eggs: Implications for the fertility care of transgender males.

Running title: Egg fertilizability in testosterone treated females

C.B. Bartels ${ }^{1,2}$, T.F. Uliasz ${ }^{1}$, L. Lestz ${ }^{1}$, and L.M. Mehlmann ${ }^{1^{*}}$

${ }^{1}$ Department of Cell Biology, UConn Health, Farmington, CT 06030, USA

${ }^{2}$ Center for Advanced Reproductive Services, Division of Reproductive Endocrinology and Infertility, Department of Obstetrics and Gynecology, UConn Health, Farmington, CT 06030, USA

${ }^{*}$ Correspondence address. Department of Cell Biology, UConn Health, 263 Farmington Ave., Farmington, CT 06030. Phone 001 860-679-2703. E-mail Imehlman@uchc.edu

Key words: transgender/fertility/testosterone/mouse model/ovary/oocyte 
STUDY QUESTION: Does testosterone use in females affect reproductive potential, particularly

2 with regard to the production of fertilizable gametes?

3 SUMMARY ANSWER: Testosterone cypionate injections given to post-pubertal female mice

4 caused virilization and ovaries were smaller than control ovaries, but ovaries were still

5 responsive to hormonal stimulation and produced fertilizable eggs when superovulated.

6 WHAT IS KNOWN ALREADY: Studies to examine the effects of testosterone on reproductive

7 potential in transgender males are lacking. Recently, a model was developed that simulates

8 many aspects of testosterone use in transgender males in order to look at reproductive effects

9 of testosterone in female mice. This study found masculinizing effects on the mice but did not

10 find significant deficits on the number of ovarian follicles; however, effects of testosterone use

11 on ovarian stimulation and fertilizability of oocytes were not investigated.

12 STUDY DESIGN, SIZE, DURATION: A total of 66, 6-week-old Hsd:NSA(CF-1) female mice and

$136 \mathrm{Hsd}: I C R(C D-1)$ mice were used for this study. Mice were injected subcutaneously with 400

$14 \mu \mathrm{g}$ testosterone cypionate or sesame oil once a week for 6 weeks and were either sacrificed a

15 week after the $6^{\text {th }}$ injection (active exposure group), or were sacrificed 6-7 weeks after the final

16 testosterone injection (washout group).

17 PARTICIPANTS/MATERIALS, SETTING, METHODS: Both active exposure and washout

18 groups were further subdivided into 3 groups: unstimulated, eCG-stimulated, or eCG/hCG-

19 stimulated. eCG-stimulated mice were sacrificed 44-48 hrs after eCG injection. eCG/hCG-

20 stimulated mice were injected with eCG, followed $48 \mathrm{hrs}$ later with hCG. Mice were sacrificed

$21 \sim 13-18$ hrs after the hCG injection. Data collected included daily vaginal cytology, terminal

22 hormone levels and ovary weights, ovarian histology, number of oocytes/eggs collected in each

23 group, and cleavage to the 2-cell stage following in vitro fertilization.

MAIN RESULTS AND THE ROLE OF CHANCE: Testosterone cypionate-treated mice had 
27 and responded to gonadotropin stimulation by ovulating similar numbers of eggs that fertilized

28 and cleaved in vitro.

29 LIMITATIONS, REASONS FOR CAUTION: Our model treated female mice for only 6 weeks,

30 whereas many transgender men use testosterone for many years before considering biological

31 children. Importantly, a mouse system may not perfectly simulate human reproductive

32 physiology.

33 WIDER IMPLICATIONS OF THE FINDINGS: The current standard of care for transgender men

34 who desire biological children is to cease testosterone therapy prior to ovarian stimulation, but

35 the necessity for stopping testosterone is not known. Our model demonstrates that it is possible

36 for testosterone-suppressed ovaries to respond to gonadotropic stimulation by producing and

37 ovulating fertilizable eggs, thereby obviating the need for testosterone cessation prior to ovarian

38 stimulation. In time, these results may provide insights for future clinical trials of fertility

39 treatment options for transgender men. 
Introduction

42 Transgender males are individuals who were assigned female at birth but identify as males.

43 Many, but not all, transgender males opt to undergo gender-affirming treatment, which can

44 consist of surgery and/or hormone therapy (HT) by long-term administration of testosterone

45 (Quinn et al., 2017). HT improves gender dysphoria through testosterone-driven development

46 and maintenance of desired male secondary sex characteristics; however, a potential adverse

47 effect of testosterone exposure is a decrease in fertility.

A recent study by the Williams Institute estimated that about 1.4 million individuals identify as transgender in the United States (Flores, 2016), and there are reports that approximately half of transgender adults desire biological children (Moravek, 2019; Wierckx et al., 2012). The reproductive consequences of $\mathrm{HT}$ are still unclear, and both the World Professional Association for Transgender Health (WPATH) and the Endocrine Society recommend that all transgender males be counseled regarding options for fertility preservation before initiating testosterone therapy (Hembree et al., 2017; Meyer, 2009). Transgender males may not consider fertility preservation to be important at the start of testosterone therapy, which can be initiated as early as 14 years old. In addition, assisted reproductive technology centers have little experience in

57 stimulation of peripubertal ovaries, nor in performing transvaginal oocyte harvest in children. Due to a variety of physiological and psychological barriers, ovarian stimulation and oocyte

59 harvest is best avoided in children, if it can be safely postponed to adulthood. A recent study showed that only 2 of $72(2.8 \%)$ young transgender individuals chose to utilize fertility preservation after counseling (Nahata et al., 2019), which reflects a priority for HT initiation to attain features of their affirmed gender while avoiding the delay, invasiveness, or costs of fertility preservation (Armuand et al., 2017; Insogna et al., 2020). The desire for biological children may 
The approach to fertility options in transgender males already taking HT therefore warrants more investigation. To date, studies to evaluate the impact of HT on reproductive potential for transgender males are lacking (ASRM Committee Opinion, 2015). The options for transgender males presenting for fertility preservation after $\mathrm{HT}$ is either surgical oophorectomy to collect ovarian tissue or surgical oocyte retrieval following ovarian stimulation (De Roo et al., 2016; Neblett and Hipp, 2019). Methods for maturation and fertilization of oocytes collected directly from isolated ovarian tissue without hormonal stimulation, while improving, are still considered to be experimental (Yang and Chian, 2018) and to date, there have been no studies to examine

73 this method for fertility preservation in transgender males. Accordingly, if a transgender male presents for fertility treatment now or in the near future and plans to have the pregnancy carried by a cis-female partner or gestational carrier, the best option is in vitro fertilization (IVF) after ovarian stimulation and oocyte retrieval. Due to the unknown effects of high-level testosterone on ovarian response and oocyte quality, the current recommended practice before IVF is discontinuation of testosterone to allow the resumption of menses (Adeleye et al., 2019; Broughton and Omurtag, 2017; Leung et al., 2018). While this treatment regimen can be effective, HT cessation for the purpose of fertility treatment has been reported to cause

81 significant psychological distress in the form of gender dysphoria attributed to the gender-

82 incongruous effects of testosterone withdrawal, estrogen exposure, and menses (Armuand et al., 2017). These negative consequences could lead to treatment avoidance even when fertility

84 is desired.

85 Ovarian tissue taken from HT-exposed transgender males has demonstrated changes including 86 a thickened cortex, stromal hyperplasia, an increased number of atretic follicles, and increased cortical stiffness (De Roo et al., 2019; Ikeda et al., 2013). However, the ovarian tissue follicular pool is not diminished (De Roo et al., 2016; Van Den Broecke et al., 2001) Markers of ovarian reserve, including anti-Müllerian hormone and inhibin, are unchanged (Rodriguez-Wallberg et 
90 al., 2014), and successful pregnancies have been reported after testosterone use (Light et al.,

91 2014). Case reports have been published of subjects successfully undergoing IVF after

92 temporarily discontinuing testosterone therapy for 1-12 months, and healthy live births were

93 reported (Adeleye et al., 2019; Broughton and Omurtag, 2017; Leung et al., 2018). These data

94 suggest that the follicular pool and oocyte quality are preserved.

95 A primary mouse model for $\mathrm{HT}$ in transgender males was recently published and found that

96 ovaries from testosterone-treated mice were generally normal, with the exception of some cyst-

97 like late antral follicles (Kinnear et al., 2019). The fertility potential in terms of ovarian response

98 to gonadotropins, oocyte integrity, or fertilizability was not examined. There is very limited

99 information about the necessity for cessation of testosterone therapy prior to ovarian

100 stimulation, and no mouse models have addressed this problem. The aim of the present study

101 was to establish a mouse model in which reproductive potential could be evaluated following

102 prolonged HT in female mice with and without a period of testosterone cessation. 
Materials and Methods

105 Ethical approval

106 Animal studies were performed in accordance with the Guide for the Care and Use of

107 Laboratory Animals (National Academy of Sciences 1996) and were approved by the Institutional Animal Care \& Use Committee at UConn Health (protocol number 101977-0122).

\section{Media and Reagents}

111 All chemicals were purchased from Millipore Sigma (St. Louis, MO, USA) unless otherwise

112 indicated. Testosterone cypionate was from Steraloids (Newport, RI, USA) and was prepared

113 as an $8 \mathrm{mg} / \mathrm{ml}$ solution in sesame oil. Equine chorionic gonadotropin (eCG) was from

114 Calbiochem. The medium for oocyte collection was HEPES-buffered MEM $\alpha$ (Gibco 12000022,

115 Thermo Fisher, Waltham, MA, USA) containing penicillin, streptomycin, and polyvinyl alcohol

116 (PVA), and $10 \mu \mathrm{M}$ milrinone to prevent spontaneous meiotic maturation (Mehlmann et al.,

117 2019). For overnight oocyte maturation, oocytes were washed into bicarbonate-buffered

118 MEM $\alpha$ (Mehlmann et al., 2019) containing 5\% fetal bovine serum (Invitrogen, Carlsbad, CA,

119 USA) without milrinone. For in vitro fertilization, cumulus masses were collected in human tubal

120 fluid medium (HTF; Cook Medical Inc. IVF medium (\#K-RVFE; Fisher) containing reduced

121 glutathione. Sperm were capacitated in IVF medium (Mehlmann and Kline, 1994) containing 15

$122 \mathrm{mg} / \mathrm{ml}$ Fraction $\mathrm{V}$ bovine serum albumin.

\section{Experimental design}

125 Six-week-old female CF-1 (Envigo, Indianapolis, IN, USA) and >8-week-old male CD-1 mice

126 (Envigo) were used for all experiments. Three female mice were housed per cage in a

127 temperature and light-controlled room on a 14L:10D light cycle. Male mice were housed

128 individually. 
130 Six-week-old female mice were lightly sedated with isoflurane and injected weekly,

131 subcutaneously, with $400 \mu \mathrm{g}$ testosterone cypionate or vehicle using 27-gauge needles. In the

132 first set of experiments, mice were sacrificed within 8 days after the $6^{\text {th }}$ testosterone injection,

133 when testosterone levels were high. These mice are referred to as the "active exposure" group.

134 In the second set of experiments, mice were sacrificed 6-7 weeks after the $6^{\text {th }}$ testosterone

135 injection, when testosterone returned to basal levels. These mice are referred to as the

136 "washout" group. Both groups were subdivided into 3 more groups: mice that were not

137 stimulated with gonadotropins; mice that were stimulated with eCG only; and mice that were

138 stimulated with eCG followed by hCG to induce ovulation.

For both the active exposure and washout groups, we performed vaginal smears to examine cyclicity. We analyzed the following: serum testosterone levels; serum estrogen levels; ovary weights and histology; oocyte number prior to and after priming with eCG or eCG + hCG; structure of the meiotic spindle; and egg fertilizability. Control mice were injected with sesame oil and were treated in parallel with the testosterone-injected groups. All mice were euthanized by isoflurane overdose followed by cervical dislocation.

\section{Vaginal cytology}

148 For the active exposure group, daily vaginal smears were performed using standard methods

149 (Goldman et al., 2007) starting in the $5^{\text {th }}$ week of testosterone treatments. For the washout 150 group, daily vaginal smears were done starting one week after the final testosterone injection.

151 Staging of the estrous cycle was determined by the presence and distribution of leukocytes, 152 cornified epithelial cells, and nucleated epithelial cells. Proestrus was identified by nucleated 153 epithelium, estrus was identified by large cornified epithelial cells, metestrus was identified by 
154 leukocytes and large cornified epithelial cells, and diestrus was identified by the predominance

155 of leukocytes in the presence of nucleated and cornified cells (Gaytan et al., 2017). Clitoral size

156 was visually assessed at the time of cytology.

157 Blood collection and hormone analysis

158 After the mice were sacrificed, they were weighed and terminal blood was collected by cardiac

159 puncture using a heparinized 18-gauge needle and syringe. Blood samples were kept on ice.

160 Within 30 minutes of collection, samples were centrifuged at $4^{\circ} \mathrm{C}$ for 15 minutes $(1000 \times g)$ and

161 supernatants were stored at $-80^{\circ} \mathrm{C}$. Diethyl ether extraction was performed as directed by

162 Cayman Chemical, with extracted samples stored at $-20^{\circ} \mathrm{C}$ in Cayman ELISA buffer.

163 Testosterone and estradiol-17 $\beta$ analyses were performed using ELISA kits (Cayman Chemical,

164 Ann Arbor, MI, USA) according to the manufacturer's instructions. For comparison, we also

165 collected blood from mature male mice that were used for in vitro fertilization (see below).

166 These males had been acclimated to the lab for at least one week prior to the experiment, were

167 housed individually, and were not exposed to females prior to blood collection.

Ovarian histology

169 Ovaries were collected and most of the fat and oviducts were removed by dissection under a

170 stereoscope and were then weighed. Ovaries were fixed in 10\% formalin for 24-48 hours,

171 washed into PBS, then were dehydrated in ethanol, embedded in paraffin, and $5 \mu \mathrm{m}$ serial

172 sections were cut and processed by the Histology Core at UConn Health. Sections were

173 stained with hematoxylin and eosin.

174 Total numbers of antral follicles and corpora lutea were counted. Antral follicles were defined as

175 being $\sim 250-320 \mu \mathrm{m}$ in diameter with a clearly visible antral cavity and oocyte with two or more

176 layers of granulosa cells. Preovulatory follicles were defined as being $>320 \mu \mathrm{m}$ in diameter.

177 Each antral follicle was counted only when the oocyte was present and while scanning between 
178

179

180

181

182

183

184

185

186

187

188

189

190

191

192

193

194

195

196

197

198

199

200

USA).

adjacent sections to prevent duplicate counting. Corpora lutea were defined as discrete eosinophilic round structures. Corpora lutea were numbered as the sections were serially assessed through the entire ovary to prevent duplicate counting. Two of the investigators independently counted follicles.

Oocyte collection and immunofluorescence staining

Ovaries from unstimulated and eCG-primed mice were weighed and one ovary from each mouse was fixed for histological analysis while the contralateral ovary was used for oocyte collection. The ovary for oocyte collection was placed in HEPES-buffered MEM $\alpha$ containing milrinone and punctured using a 30-gauge needle. Oocytes were collected with a mouth pipet and counted. For in vitro maturation, oocytes were washed into bicarbonate-buffered MEM $\alpha$ without milrinone and were incubated overnight at $37^{\circ} \mathrm{C}$ in a humidified incubator containing $5 \%$ $\mathrm{CO}_{2} / 95 \%$ air. In vitro maturation was confirmed by the disappearance of the nuclear envelope and the formation of first polar bodies using a stereoscope. Oocytes were fixed for 30-60 min at

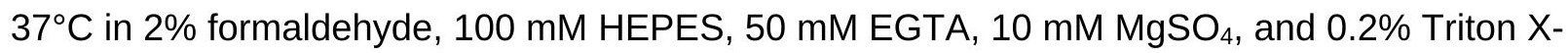
100, then were permeabilized in PBS containing 0.1\% Triton X-100, and blocked for at least 15 minutes in PBS containing 3\% BSA and 0.01\% Triton X-100. Oocytes were incubated overnight at $4^{\circ} \mathrm{C}$ in primary antibody against tubulin (YL1/2; Serotec Inc., Raleigh, NC) diluted to $10 \mu \mathrm{g} / \mathrm{ml}$ in blocking buffer. After washing in PBS-PVA, oocytes were incubated in Alexa488-conjugated secondary antibody for $1 \mathrm{hr}$ at room temperature in the dark. Oocytes were washed in PBSPVA containing $5 \mu \mathrm{M}$ SYTOX Orange (ThermoFisher) to label chromosomes. Imaging for spindle integrity was performed using a Zeiss Pascal confocal microscope with a 40X, 1.2 NA water immersion objective (C-Apochromat; Carl Zeiss Microlmaging, Inc., Thornwood, NY, 
203 Female mice were superovulated with 5 IU eCG, followed 48 hrs later with 5 IU hCG.

204 Approximately 13-15 hrs later, ovaries and oviducts were removed and cumulus masses

205 obtained by puncturing the swollen ampullae. Cumulus masses were incubated in $200 \mu$ drops

206 of HTF containing reduced glutathione for $\sim 30$ min prior to adding sperm. Sperm were collected

207 from the epididymides of male mice by gently snipping with fine scissors into a $100 \mu$ drop of

208 capacitation medium and were capacitated for $1-2$ hrs before adding 3-5 $\mu$ of the sperm

209 suspension to the drops containing the eggs. The sperm and eggs were incubated together for

$2104 \mathrm{hrs}$, then were washed into $200 \mu \mathrm{l}$ drops of HTF without glutathione. Fertilized eggs were

211 incubated overnight in a humidified incubator containing 5\% CO2/95\% air. The next day, 2-cell

212 embryos were counted.

213 Statistical analysis

214 Statistical analyses were performed using Prism 6.0 software for Windows, GraphPad Software,

215 La Jolla, California (www.graphpad.com). Specific statistical tests for each experiment are

216 indicated in the figure legends. $\mathrm{P}<0.05$ was considered to be significant. 
222 Results

223

224 Testosterone cypionate elevates serum testosterone levels and induces virilization in female

225 mice.

226 In a recent study investigating the effects of testosterone on female mice, Kinnear et al. (2019)

227 injected testosterone enanthate twice weekly to maintain elevated testosterone levels. In the

228 current study, we injected a similar form of testosterone, testosterone cypionate (referred to

229 hereafter as "T"), which is commonly used by transgender men to elevate T levels (Luthy et al.,

230 2017; Moravek et al., 2020), weekly. T-injected mice showed signs of virilization, including

231 distinct clitoromegaly and cessation of estrous cycles (Fig. 1A). All control-injected mice clearly

232 cycled throughout the entire experiment, whereas all T-injected mice appeared to be in diestrus

233 (Fig.1B), which is consistent with what was observed previously (Kinnear et al., 2019). One

234 week after the $6^{\text {th }} \mathrm{T}$ injection (referred to herein as the "active exposure" group), mice were

235 sacrificed, trunk blood was collected, and T levels were measured. T-injected mice had

236 significantly higher T levels than controls, and the amount of T was comparable to the levels in

237 adult males (Fig. 2). In one set of experiments, we did not sacrifice females after the 6-week

238 injection period; rather, the mice were kept for several weeks after cessation of injections

239 (referred to herein as the "washout" group). T levels declined to baseline levels within 5 weeks

240 following the last injection (Fig. 2) and these "washout mice" resumed cycling, as assessed by

241 daily vaginal smears. Interestingly, clitoromegaly was no longer apparent in these washout

242 mice 5 weeks after the last injection (Fig. 1A). The weights of the mice did not differ between T-

243 treated and controls. T-treated and control mice in the active exposure group weighed $30.5 \pm$

$2440.8 \mathrm{~g}(\mathrm{SEM})$ vs $31 \pm 1 \mathrm{~g}$, respectively, whereas in the washout group T-treated and control mice

245 weighed $33.9 \pm 1$ and $33.7 \pm 0.8 \mathrm{~g}$, respectively. 
Ovaries from $T$-treated mice are smaller than control ovaries but contain normal complements of follicles and respond to stimulation by gonadotropins.

Currently, little is known about the effects of $\mathrm{T}$ treatment on the ability of ovaries to respond to gonadotropic stimulation. To investigate this, both the active exposure and washout groups of mice were divided into 3 sub-groups: 1) not stimulated by gonadotropins; 2) stimulated with eCG only; and 3) stimulated with eCG and hCG to induce ovulation. For groups 1 and 2, ovaries were collected after euthanasia, most of the fat and oviducts were removed under a stereoscope, one ovary was fixed and processed for histological analysis, and oocytes were collected from the other ovary. For group 3, ovulated eggs were collected from both oviducts prior to weighing ovaries.

Ovaries from T-treated mice in the active exposure group weighed significantly less than control ovaries whether or not they were stimulated with gonadotropins (Fig. 3A). Notably, the lower ovarian weights were still apparent in the washout group, which more closely mimics the standard of care for T-treated transgender males who wish to obtain functional eggs (Fig. 3B).

Histological analysis of unstimulated, eCG-stimulated, and ovulated ovaries from the active exposure groups (approximately 12 weeks in age) showed similar follicle morphology and comparable numbers of follicles from T-treated mice with their respective controls, despite the

267 overall smaller size of ovaries in T-treated mice (Fig. 4). Because the numbers of preantral and 268 primary follicles have already been reported to be the same for control and T-treated ovaries 269 (Kinnear et al., 2019), we focused on counting antral follicles of various sizes. We analyzed 270 follicles in detail from 3 mice per group, one ovary from each mouse. In the unstimulated group, 271 T-treated and control ovaries contained similar numbers of antral follicles, as well as similar 272 numbers of atretic follicles. Most of the atretic follicles were in the 250-320 $\mu \mathrm{m}$ size range, while 
273 there were almost no atretic follicles in the preovulatory size range. The major difference

274 between T-treated, unstimulated ovaries and control ovaries was a significantly lower number of

275 corpora lutea (CLs) in the T-treated group compared with controls (Fig. 4). The eCG-stimulated

276 ovaries contained significantly more preovulatory follicles than the unstimulated ovaries in both

277 control and T-treated mice and contained 0-1 atretic preovulatory follicles. Similar to

278 unstimulated ovaries, ovaries from T-treated mice contained fewer CLs than controls. Most of

279 the CLs present in the T-treated ovaries were likely to be from cycles that occurred prior to T

280 treatment, as they were eosinophilic rather than basophilic (Gaytan et al., 2017) and, in general,

281 located deep within the ovary rather than at the periphery (Fig. 4). The one exception was a T-

282 treated mouse that ovulated in response to the eCG injection; this mouse contained mostly

283 basophilic CLs (Fig. 4A). We did not evaluate ovulated ovaries in detail with histology.

Measurements of estradiol-17 $\beta$ (E2) levels from trunk blood obtained at the time of sacrifice

provided further evidence that T-stimulated ovaries responded to gonadotropins: E2 was low in

the unstimulated groups, increased in response to eCG injection, then fell back to basal levels

after ovulation (Fig. 5). E2 levels in T-treated mice in both the active exposure group and the

washout group were lower than respective controls in response to eCG stimulation, and E2

levels in the eCG-stimulated mice from the washout group were $\sim 3 X$ higher than in the active

exposure group (Fig. 5), though the basal levels in the unstimulated and ovulated groups were

291 similar to those in the active exposure group.

T-treated mice contain comparable numbers of meiotically competent oocytes and ovulate similar numbers of fertilizable, mature eggs as controls. 
ovulated eggs from the groups that were injected with both eCG and hCG. In the active exposure group, we recovered significantly more immature oocytes from the T-exposed ovaries than from their respective controls (Fig. 6A). In the washout group, we obtained similar numbers of immature oocytes from T-treated and control ovaries, though statistical analysis was not possible in this group due to the small sample size (n=2; Fig. 6B). Both active exposure and washout groups contained similar numbers of ovulated eggs for T-treated and control mice (Fig. 6A,B). Immature oocytes from T-treated ovaries (active exposure and washout groups) underwent germinal vesicle breakdown (GVBD), extruded first polar bodies, and formed 306 morphologically normal meiotic spindles in culture (Fig. 6C,D). The proportion of oocytes with 307 intact spindle structure vs poor spindle structure - characterized by degeneration or misaligned 308 chromosomes - was similar between the groups (Fig. 6D). The diameters of in vitro matured eggs from the active exposure T group were the same as controls (Fig. 6E).

We tested the fertilizability of ovulated eggs using in vitro fertilization by evaluating the number of 2-cell embryos that were observed $24 \mathrm{hrs}$ after insemination. Overall, cleavage to the 2-cell

312 stage was comparable between T-treated and control mice, and was similar to percentages of 313 fertilized eggs obtained from the washout group (Fig. 7). 
Discussion

317 Transgender men who have been undergoing testosterone therapy and who wish to obtain eggs

318 for fertilization or freezing are generally stimulated with gonadotropins. This is usually done

319 following a period of $\mathrm{T}$ cessation that is sufficient for the menstrual cycle to resume (Adeleye et

320 al., 2019; Broughton and Omurtag, 2017; Leung et al., 2018). There is strong evidence that

321 transgender men who have taken T can produce viable, developmentally competent eggs after

322 discontinuing its use (Adeleye et al., 2019; Broughton and Omurtag, 2017; Leung et al., 2018;

323 Light et al., 2014), but to date, there are no publications regarding the quality and

324 developmental capacity of eggs retrieved from transgender men who remain on HT. Here, we

325 show that treating female mice with T cypionate weekly for 6 weeks does not impair the

fertilizability of their eggs, and our results suggest that $T$ treatment does not need to stop before

327 gonadotropic stimulation.

T cypionate elevated blood T levels to those found in male mice, stopped the estrous cycle, and caused significant clitoral growth, changes that are commonly observed in transgender males on HT (Unger, 2016). It was noteworthy that the clitoromegaly did not persist in the washout group, which was surprising because it is generally recognized that this is a permanent change in human females exposed to high levels of T (Cabrera and Rogol, 2013; Sielert et al., 2013). It

334 is possible that the regression of clitoromegaly upon T withdrawal in our mice represents a 335 difference between mice and humans; however, careful measurements using a larger sample 336 size would need to be done to determine this definitively.

338 T-treated mice had smaller ovaries than controls, which is likely due to the greatly reduced 339 number of CLs in these mice. A recent study reported a complete absence of CLs in T-treated 340 female mice (Kinnear et al., 2019). The finding that our T-treated mice had CLs at all was 
341

342

unexpected, as we used a concentration of $T$ cypionate that was similar to the mid-range effective dose used by Kinnear et al. In general, the eosinophilic staining of CLs we observed in T-treated mice was consistent with residual rather than freshly ovulated CLs (Gaytan et al., 2017) and there were considerably fewer CLs in our T-treated mice than in controls, suggesting that the estrous cycle was indeed inhibited in our mice, as was also shown by vaginal cytology. Smaller ovaries were also apparent in T-treated mice in the washout group, which likewise contained significantly fewer CLs than controls, suggesting that these mice had only recently begun cycling prior to ovary harvest and therefore had many fewer ovulations than controls.

Although they weighed less than controls, the ovaries from T-treated mice contained a complement of histologically normal antral follicles that were similar to controls. Unlike the study by Kinnear et al. (2019), who reported a higher incidence of late-stage atretic, cyst-like follicles, we only observed a single preovulatory atretic follicle in 3/6 ovaries examined, which was not significantly different from controls. Rather, the majority of atretic antral follicles we observed came from follicles that were in the $-250-320 \mu \mathrm{m}$ diameter size range, not yet preovulatory, and the percentages were not different between control and T-treated ovaries. Ttreated ovaries that were stimulated by eCG had more preovulatory follicles than unstimulated ovaries, and these numbers were comparable to the number of preovulatory follicles observed in control mice. One of the T-treated mice unexpectedly ovulated in response to eCG stimulation. There is evidence that $\mathrm{T}$ induces the expression of $\mathrm{FSH}$ receptors in granulosa cells (Garcia-Velasco et al., 2012; Liu et al., 2015; Sen et al., 2014), and if this occurred in our mice, then it is possible that the T-treated follicles were sensitized to eCG such that spontaneous ovulation occurred prior to the administration of hCG.

T-treated mice responded to eCG treatment by producing E2. Interestingly, T-treated mice in the active exposure group did not elevate E2 to the same extent as controls. The difference in 
E2 levels after eCG was surprising because a similar number of oocytes were collected after stimulation. In human IVF cycles, the peak E2 level achieved directly correlates with the number of oocytes collected at the time of retrieval (Chenette et al., 1990), and during reported IVF cycles in transgender males, the peak E2 levels, as well as the number of oocytes collected, have been reported to be similar to female controls, although higher doses of gonadotropins were used for transgender males (Leung et al., 2018). Lower E2 levels here may

373 reflect the lower number of CLs in the T group. Though it is thought that CLs are rapidly

374 inactivated after each cycle in mice (Accialini et al., 2017), it is possible that the residual CLs retain some ability to produce $\mathrm{E} 2$ in response to eCG.

377 Ovaries from T-treated mice produced meiotically competent oocytes. Oocytes retrieved from unstimulated and eCG-stimulated, T-treated ovaries were able to mature to the metaphase II stage in culture, forming morphologically normal meiotic spindles. This is consistent with a descriptive study of human oocytes collected from the ovarian cortex of HT-exposed transgender males, in which oocyte meiotic spindle structure after in vitro maturation was found to be normal (Lierman et al., 2017). In addition, T-treated mice in both the active exposure and washout groups ovulated similar numbers of eggs in response to eCG and hCG injection as controls. These eggs fertilized to the same extent as controls and cleaved to the 2-cell stage. poor-quality eggs, none of which fertilized. One hypothesis is that this mouse ovulated

387 prematurely, as there was some histological evidence in a different T-treated mouse of 388 premature ovulation after eCG. There was insufficient data to fully explore this isolated 389 scenario, and the other T-treated mice produced fertilizable eggs. 
In conclusion, we provide evidence showing that female mice produce normal, fertilizable eggs after testosterone exposure, whether T levels are low after a washout period or high during active exposure. One limitation in our study could be that we only exposed mice to T for 6 weeks. While this length of exposure was sufficient to produce phenotypes characteristic of human transgender males exposed to $\mathrm{T}$, it may not completely mimic the human situation, in which many transgender males seeking fertility treatment have been on HT for several years. Further studies that expose mice to $T$ for longer periods of time would help confirm that

398 its effects are not detrimental to the reproductive process. Despite this concern, our results

399 provide promising data that could help influence the treatment options for transgender men

400 seeking fertility treatment. If testosterone has no detrimental impact on ovarian function,

401 transgender males will have greater flexibility in making reproductive decisions. It is important

402 to note, however, that if a transgender male plans to become pregnant by spontaneous pregnancy or use of assisted reproductive technology, testosterone must be discontinued due to

404 its teratogenic effects (De Roo et al., 2016). Our study suggests that the current practice of T cessation prior to ovarian stimulation and surgical oocyte retrieval may not be necessary when the transgender male does not plan to carry the pregnancy at that time, and could potentially

407 help serve as the basis for human trials to examine this current clinical practice.

410 T.F.U. contributed to the study design, data acquisition, and article review. L.L. contributed to

411 data acquisition and article review. L.M.M. designed the study, contributed to data acquisition

412 and interpretation, and helped draft the article. 
415 Acknowledgements

416 The authors thank Dr. Daniel Grow, M.D. and director of the Center for Advanced Reproductive

417 Services Fellowship Program at UConn Health; and Drs. Laurinda Jaffe, Ph.D., Bruce White,

418 Ph. D, and John Nulsen, M.D. for support and helpful advice, discussions, and suggestions on

419 the manuscript.

$420 \quad$ Funding

421 This study was funded by the Reproductive Endocrinology and Infertility fellowship program

422 through UConn Health Graduate Medical Education (to C.B.B.).

423 Conflict of interest

424 The authors have no competing interests.

425

426 
428 Accialini P, Hernandez S, Abramovich D, Tesone M. The Rodent Corpus Luteum. In Meidan R

429 (ed) The Life Cycle of the Corpus Luteum. 2017 Springer International Publishing, New York, NY, pp 117-131.

Adeleye AJ, Cedars MI, Smith J, Mok-Lin E. Ovarian stimulation for fertility preservation or family building in a cohort of transgender men. J Assist Reprod Genet 2019;36: 2155-2161.

Armuand G, Dhejne C, Olofsson Jl, Rodriguez-Wallberg KA. Transgender men's experiences of fertility preservation: a qualitative study. Hum Reprod 2017;32: 383-390.

Broughton D, Omurtag K. Care of the transgender or gender-nonconforming patient undergoing in vitro fertilization. Int. J Transgenderism 2017;18: 372-375.

437 Cabrera SM, Rogol AD. Testosterone exposure in childhood: discerning pathology from physiology. Expert Opin Drug Saf 2013;12: 375-388.

Chenette PE, Sauer MV, Paulson RJ. Very high serum estradiol levels are not detrimental to clinical outcome of in vitro fertilization. Fertil Steril 1990;54: 858-863.

De Roo C, Tilleman K, T'Sjoen G, De Sutter P. Fertility options in transgender people. Int Rev Psych 2016;28: 112-119.

De Roo C, Tilleman K, Vercruysse C, Declercq H, T'Sjoen G, Weyers S, De Sutter P. Texture profile analysis reveals a stiffer ovarian cortex after testosterone therapy: a pilot study. $J$ Assist Reprod Genet 2019;36: 1837-1843.

Flores AR, Herman, J.L., Gates, G.J., Brown, T.N.T. How many adults identify as transgender in the United States? Los Angeles, CA: The Williams Institute 2016.

448 Garcia-Velasco JA, Rodriguez S, Agudo D, Pacheco A, Schneider J, Pellicer A. FSH receptor in 449 vitro modulation by testosterone and hCG in human luteinized granulosa cells. Eur J Obstet Gynecol Reprod Biol 2012;165: 259-264. 
451

452

453

454

455

456

457

458

459

460

461

462

463

464

465

466

467

468

469

470

471

472

473

474

475

476

Gaytan F, Morales C, Leon S, Heras V, Barroso A, Avendano MS, Vazquez MJ, Castellano JM, Roa J, Tena-Sempere M. Development and validation of a method for precise dating of female puberty in laboratory rodents: The puberty ovarian maturation score (Pub-Score). Sci Rep 2017;7: 46381.

Goldman JM, Murr AS, Cooper RL. The rodent estrous cycle: characterization of vaginal cytology and its utility in toxicological studies. Birth Defects Res B Dev Reprod Toxicol 2007;80: 84-97.

Hembree WC, Cohen-Kettenis PT, Gooren L, Hannema SE, Meyer WJ, Murad MH, Rosenthal SM, Safer JD, Tangpricha V, T'Sjoen GG. Endocrine Treatment of GenderDysphoric/Gender-Incongruent Persons: An Endocrine Society Clinical Practice Guideline. J Clin Endocrinol Metab 2017;102: 3869-3903.

Ikeda K, Baba T, Noguchi H, Nagasawa K, Endo T, Kiya T, Saito T. Excessive androgen exposure in female-to-male transsexual persons of reproductive age induces hyperplasia of the ovarian cortex and stroma but not polycystic ovary morphology. Hum Reprod 2013;28: 453-461.

Insogna IG, Ginsburg E, Srouji S. Fertility Preservation for Adolescent Transgender Male Patients: A Case Series. J Adolesc Health 2020.

Kinnear HM, Constance ES, David A, Marsh EE, Padmanabhan V, Shikanov A, Moravek MB. A mouse model to investigate the impact of testosterone therapy on reproduction in transgender men. Hum Reprod 2019:34: 2009-2017.

Leung A, Sakkas D, Pang S, Thornton K, Resetkova N. ART outcomes in female to male transgender patients: a new frontier in reproductive medicine. Fert Steril 2018;109: e35.

Lierman S, Tilleman K, Braeckmans K, Peynshaert K, Weyers S, T'Sjoen G, De Sutter P. Fertility preservation for trans men: frozen-thawed in vitro matured oocytes collected at the time of ovarian tissue processing exhibit normal meiotic spindles. J Assist Reprod Genet 2017;34: 1449-1456. 
477

478

479

480

481

482

483

484

485

486

487

488

489

490

491

492

493

494

495

496

497

498

499

500

501

Light AD, Obedin-Maliver J, Sevelius JM, Kerns JL. Transgender men who experienced pregnancy after female-to-male gender transitioning. Obstet Gynecol 2014;124: 1120-1127.

Liu T, Cui YQ, Zhao H, Liu HB, Zhao SD, Gao Y, Mu XL, Gao F, Chen ZJ. High levels of testosterone inhibit ovarian follicle development by repressing the FSH signaling pathway. $\mathrm{J}$ Huazhong Univ Sci Technolog Med Sci 2015;35: 723-729.

Luthy K, Williams C, Freeborn D, Cook A. Comparison of testosterone replacement therapy medications in the treatment of hypogonadism. J Nurse Pract 2017;13: 241-249.

Mehlmann LM, Kline D. Regulation of intracellular calcium in the mouse egg: calcium release in response to sperm or inositol trisphosphate is enhanced after meiotic maturation. Biol Reprod 1994;51: 1088-1098.

Mehlmann LM, Uliasz T, Lowther KM. SNAP23 is required for constitutive and regulated exocytosis in mouse oocytes. Biol Reprod 2019;101: 338-346.

Meyer WJ. World professional association for transgender health's standards of care requirements of hormone therapy for adults with gender identity disorder. Int $\mathrm{J}$ Transgenderism 2009;11: 127-132.

Moravek MB. Fertility preservation options for transgender and gender-nonconforming individuals. Curr Opin Obstet Gynecol 2019;31: 170-176.

Moravek MB, Kinnear HM, George J, Batchelor J, Shikanov A, Padmanabhan V, Randolph JF. Impact of Exogenous Testosterone on Reproduction in Transgender Men. Endocrinology 2020;161.

Nahata L, Chen D, Moravek MB, Quinn GP, Sutter ME, Taylor J, Tishelman AC, Gomez-Lobo V. Understudied and Under-Reported: Fertility Issues in Transgender Youth-A Narrative Review. J Pediatr 2019;205: 265-271.

Neblett MF, 2nd, Hipp HS. Fertility Considerations in Transgender Persons. Endocrinol Metab Clin North Am 2019;48: 391-402. 
502

503

504

505

506

507

508

509

510

511

512

513

514

515

516

517

518

519

520

521

522

Quinn VP, Nash R, Hunkeler E, Contreras R, Cromwell L, Becerra-Culqui TA, Getahun D, Giammattei S, Lash TL, Millman A et al. Cohort profile: Study of Transition, Outcomes and Gender (STRONG) to assess health status of transgender people. BMJ Open 2017;7: e018121.

Rodriguez-Wallberg KA, Dhejne C, Stefenson M, Degerblad M, Olofsson Jl. Preserving eggs for men's fertility. a pilot experience with fertility preservation for female-to-male transsexuals in Sweden. Fert Steril 2014;102: e160-e161.

Sen A, Prizant H, Light A, Biswas A, Hayes E, Lee HJ, Barad D, Gleicher N, Hammes SR. Androgens regulate ovarian follicular development by increasing follicle stimulating hormone receptor and microRNA-125b expression. Proc Natl Acad Sci U S A 2014;111: 3008-3013.

Sielert L, Liu C, Nagarathinam R, Craig LB. Androgen-producing steroid cell ovarian tumor in a young woman and subsequent spontaneous pregnancy. J Assist Reprod Genet 2013;30: 1157-1160.

Unger CA. Hormone therapy for transgender patients. Transl Androl Urol 2016;5: 877-884.

Van Den Broecke R, Van Der Elst J, Liu J, Hovatta O, Dhont M. The female-to-male transsexual patient: a source of human ovarian cortical tissue for experimental use. Hum Reprod 2001;16: 145-147.

Wierckx K, Van Caenegem E, Pennings G, Elaut E, Dedecker D, Van de Peer F, Weyers S, De Sutter P, T'Sjoen G. Reproductive wish in transsexual men. Hum Reprod 2012;27: 483487. 
Figure legends.

523 Figure 1. T treatment induces virilization in female mice. A) Clitoromegaly was apparent in the 524 active exposure group ( $a=$ control; $b=T$-treated), but was no longer apparent in the washout 525 group (c=control; d=T-treated). B) Vaginal smears from a cycling, control mouse (a-e) and a Ttreated mouse $(\mathrm{f}-\mathrm{j})$. Smears were obtained during the fifth week of $\mathrm{T}$ injections. Shown here is

5275 sequential days of a representative control and T-injected mouse. $a=$ diestrus; $b=$ diestrus into proestrus; $c=$ proestrus; $d=e$ strus; $e=$ metestrus from a control mouse. $f-j=T$-injected mouse in diestrus.

Figure 2. Testosterone cypionate transiently elevates T levels to those of untreated adult males. T levels were significantly higher in the active exposure mice, which were tested

532 following the $6^{\text {th }} \mathrm{T}$ injection. $\mathrm{T}$ levels declined to baseline levels by 5 weeks after the last 533 injection. Different letters above the bars indicate statistical significance; $P<0.0001$, as 534 determined by one-way ANOVA.

Figure 3. Ovaries from T-treated mice weigh less than control ovaries. A) Ovary weights from

537 mice in the active exposure group. B) Ovary weights from mice in the washout group. Bars with 538 different letters are significantly different $(P<0.05)$, as determined using 2-way ANOVA followed by Bonferroni's multiple comparison test.

Figure 4. Ovaries from T-treated mice have normal complements of antral follicles but fewer corpora lutea. A) Histology sections showing representative images through ovaries from unstimulated and eCG-stimulated control and T-treated mice from the active exposure group 544 using $2 \mathrm{X}, 4 \mathrm{X}$, or $10 \mathrm{X}$ objectives. $\mathrm{C}=$ control; $\mathrm{T}=$ testosterone; * = corpus luteum. The bottommost 545 image is from a T-treated mouse that ovulated in response to eCG stimulation, showing fresh 546 CLs $\left(f^{\star}\right)$ and residual CLs $\left(r^{\star}\right)$. B) Quantification of antral follicles in unstimulated and eCG- 
547 stimulated control and T-treated mice. "Small antral" follicles measured $\sim 250-320 \mu \mathrm{m}$ in

548 diameter; "preovulatory" follicles measured $>320 \mu \mathrm{m}$ in diameter. ${ }^{* \star} \mathrm{P}<0.01$ (unpaired t-test); ***

$549 \mathrm{P}<0.0001$ (unpaired t-test). The increase in preovulatory follicles from eCG-stimulated ovaries

550 compared to unstimulated ovaries is significant $(\mathrm{P}<0.05$; 2-way ANOVA followed by Bonferroni's

551 multiple comparison test). Data are mean \pm SEM.

553 Figure 5. eCG stimulates E2 production in control and T-treated mice in both the active exposure and washout groups. Bars with different letters are significantly different $(P<0.05$; 2way ANOVA, Bonferroni's multiple comparison post-test). Data are mean \pm SEM.

Figure 6. T-treated mice produce meiotically competent oocytes and ovulate comparable numbers of eggs as controls. A,B) Numbers of oocytes and ovulated eggs recovered per ovary in the active exposure (A) and washout group (B). Bars are mean $\pm S E M ; P<0.05$ was considered significant, as determined by two-way ANOVA followed by Bonferroni's multiple comparison test. C) Representative meiotic spindles from in vitro matured, eCG-stimulated ovaries from the active exposure group. Green = tubulin; Red = DNA. D) Percentage of eggs that formed normal meiotic spindles following in vitro maturation. Bars are mean \pm SEM.

564 Numbers over each bar are the total number of in vitro matured eggs. AE = active exposure; $\mathrm{WO}=$ washout. E) Diameters of in vitro matured eggs in control vs. T-treated mice.

567 Figure 7. Eggs from T-treated mice are fertilizable. Completed fertilization rates, defined as the 568 number of 2-cell embryos per the number of inseminated eggs, in control vs. T-treated mice in 569 both active exposure (A) and washout (B) groups. Each dot represents a single mouse.

570 Horizontal bars are the mean and the vertical bars are \pm SEM. 




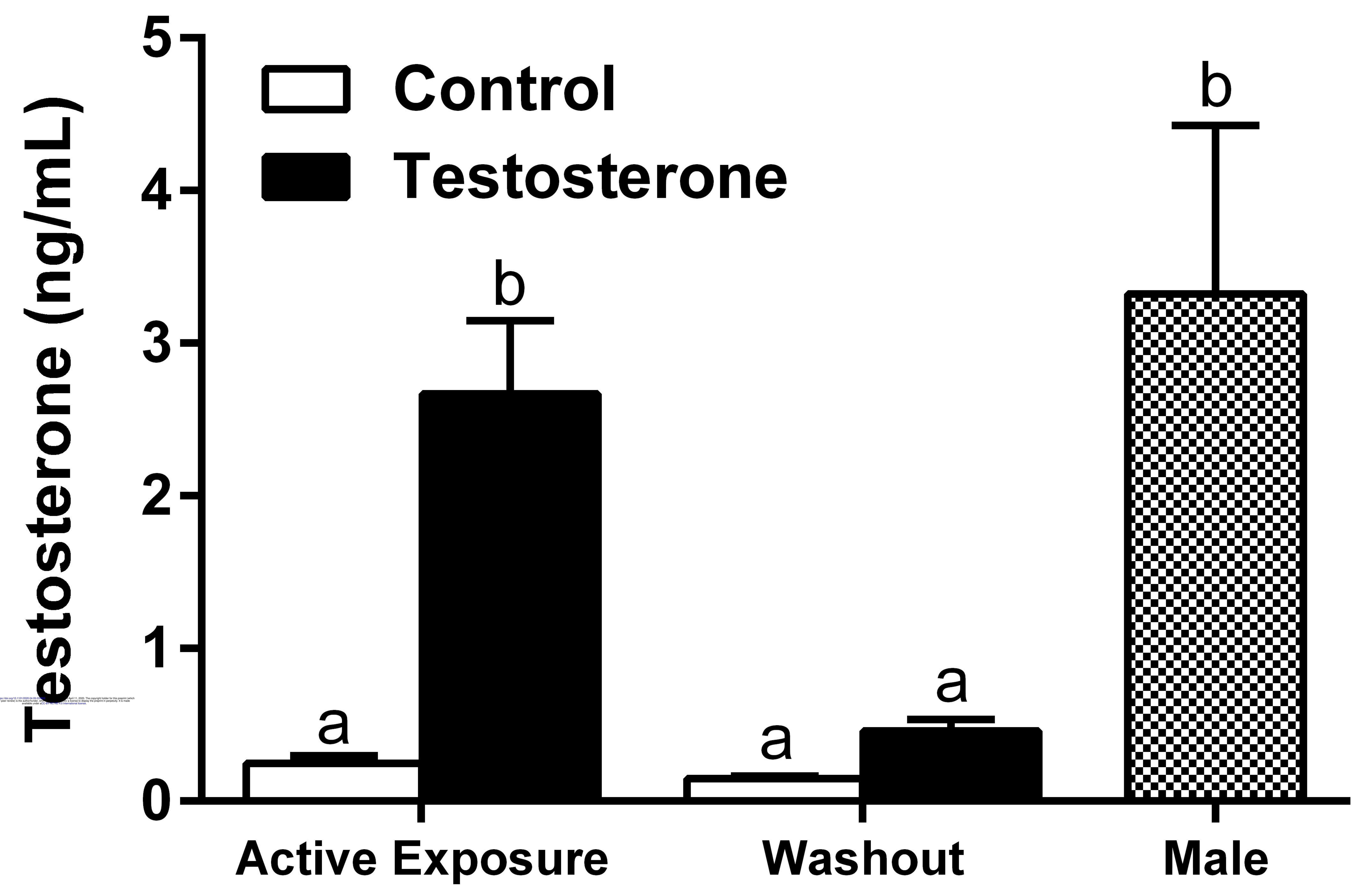




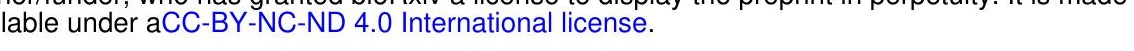

A

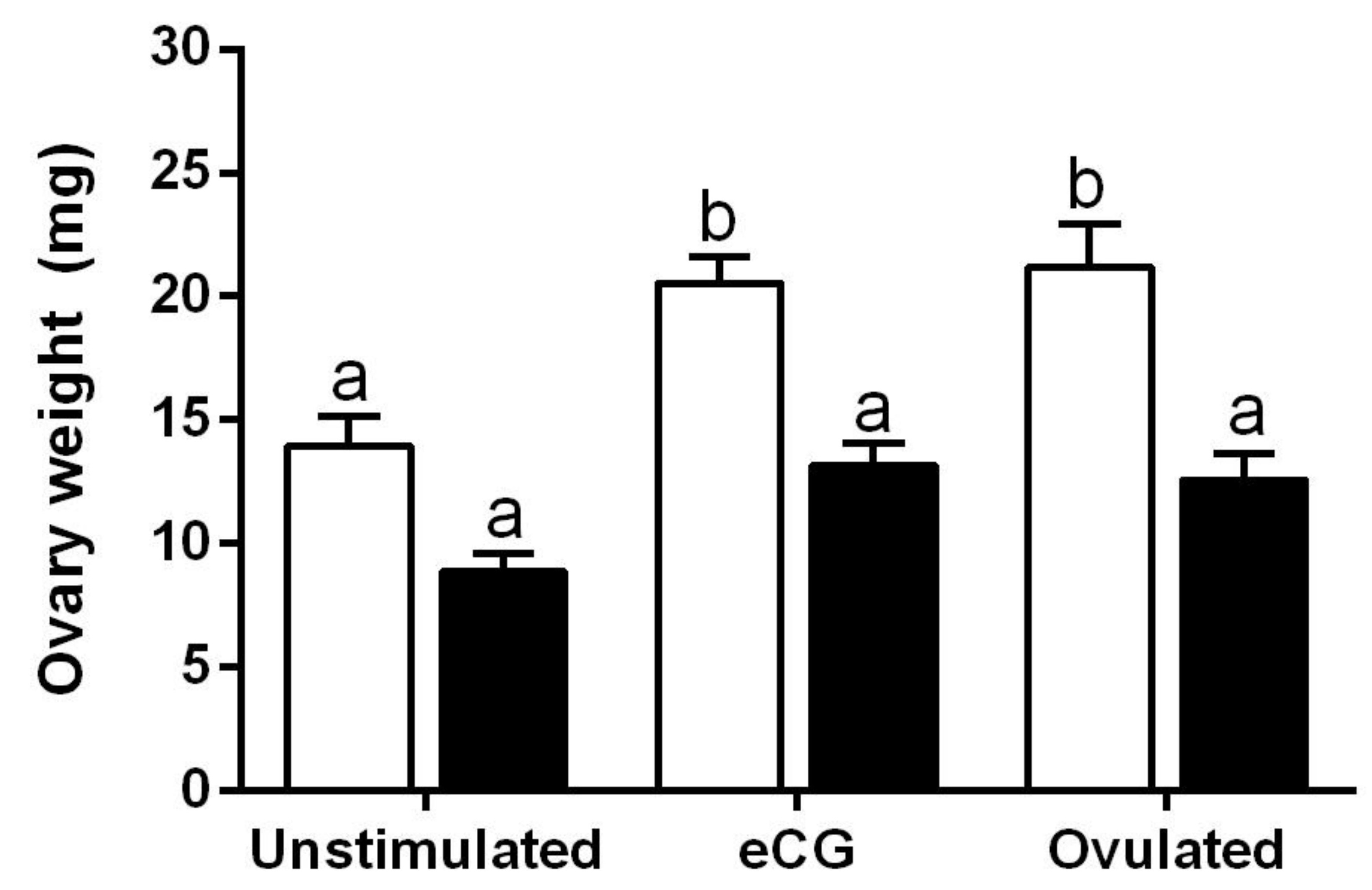

B

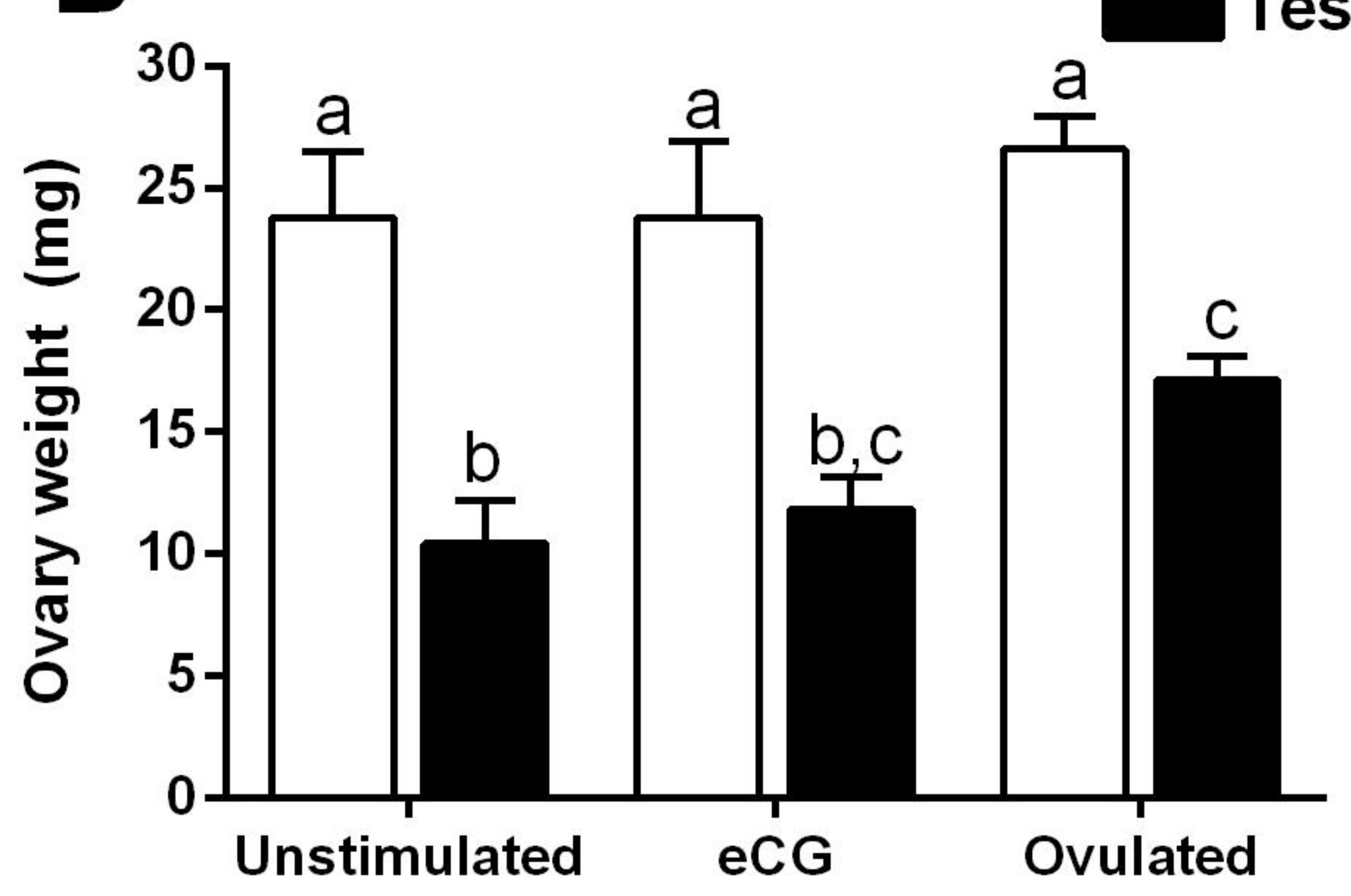




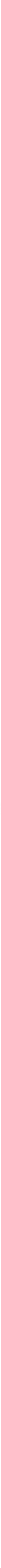


A

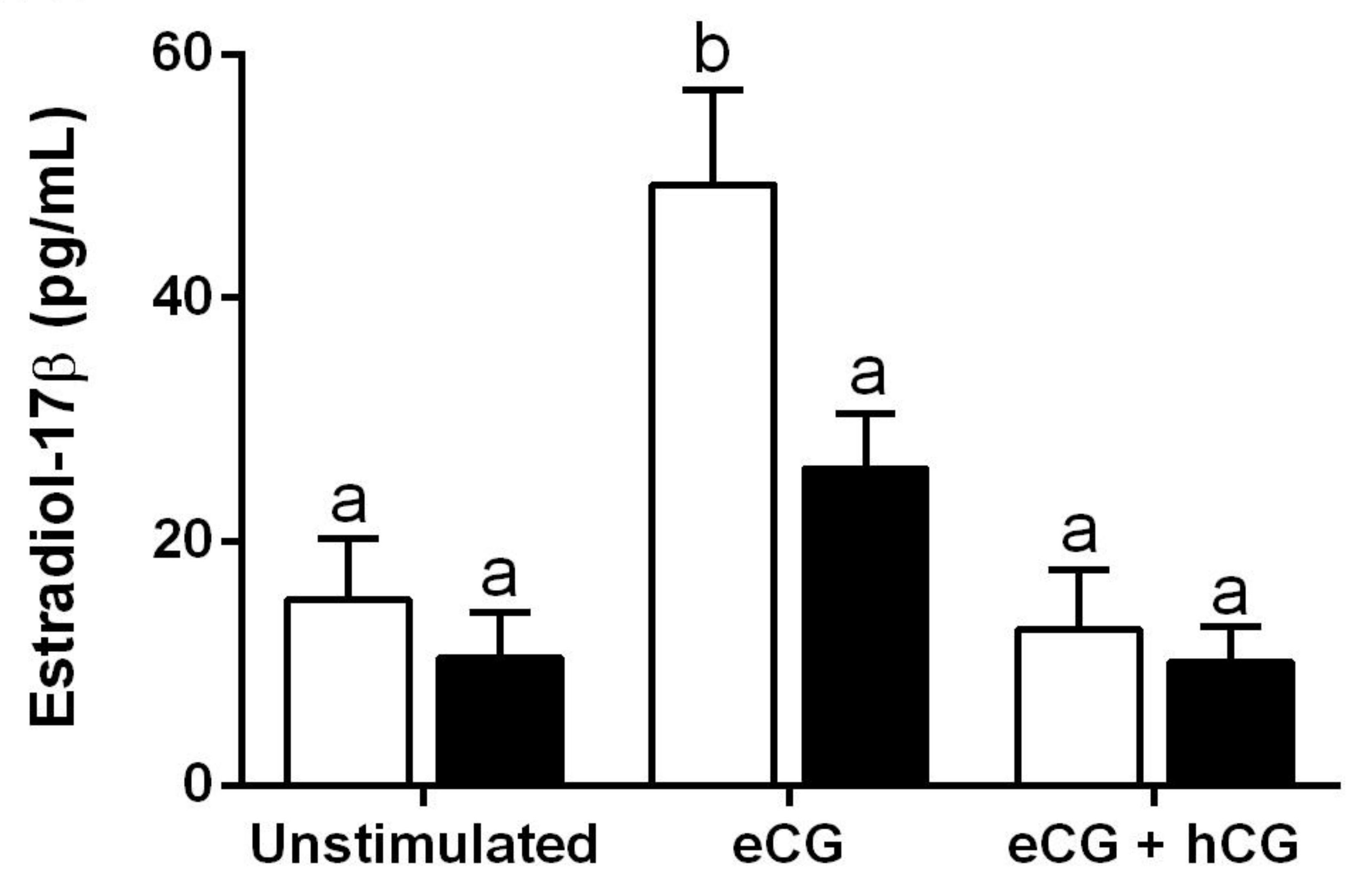

B

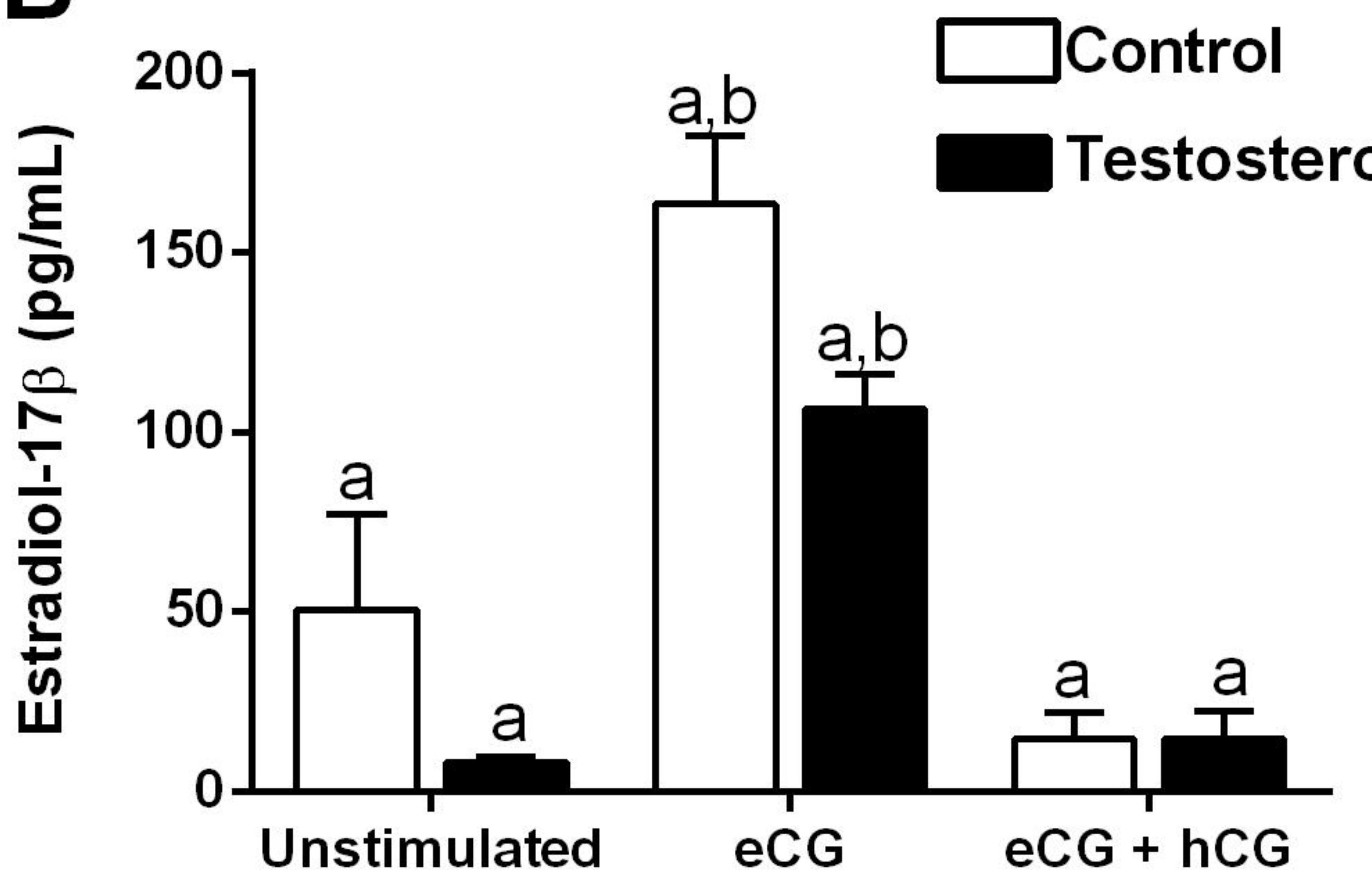


A

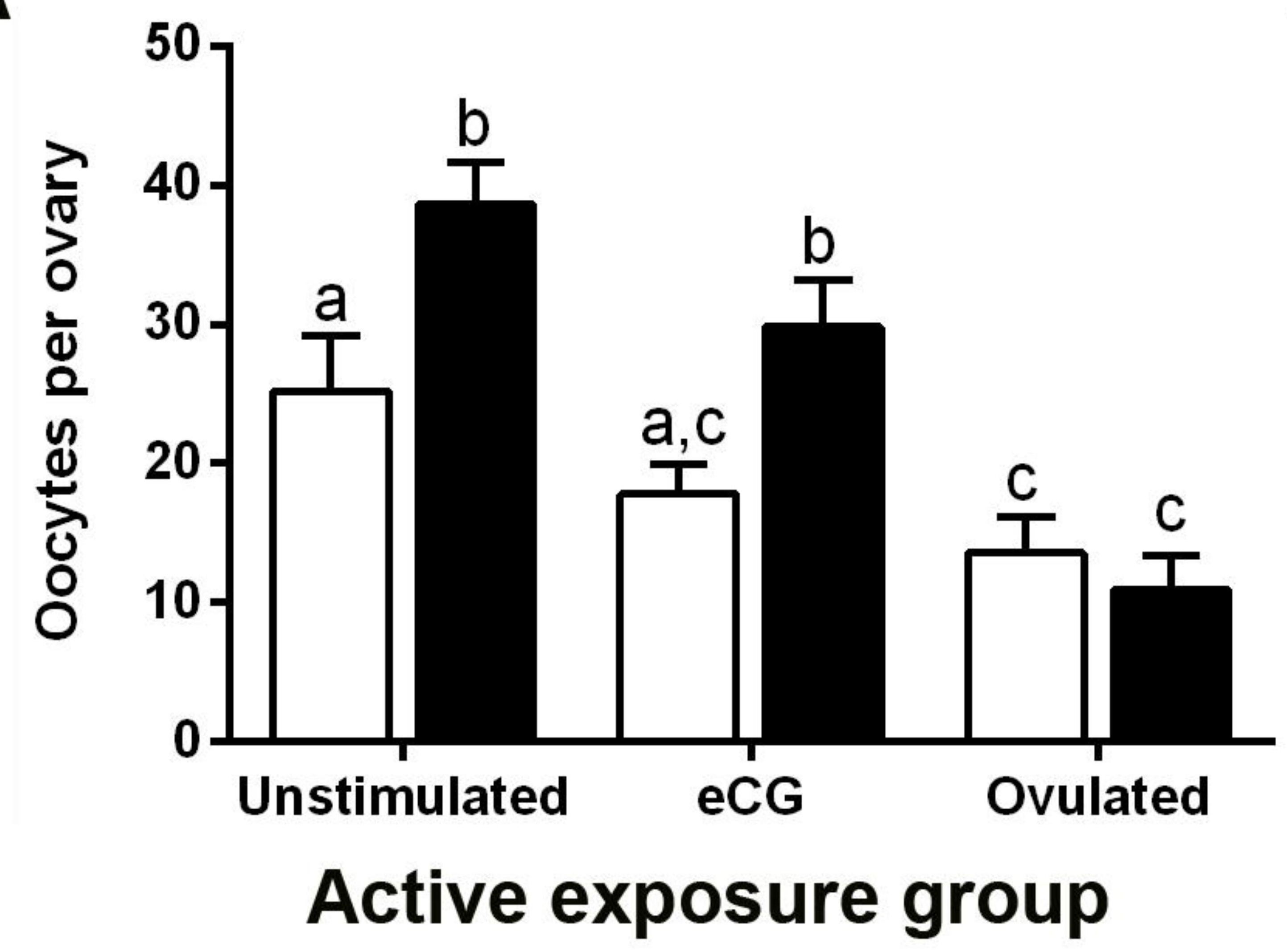

C
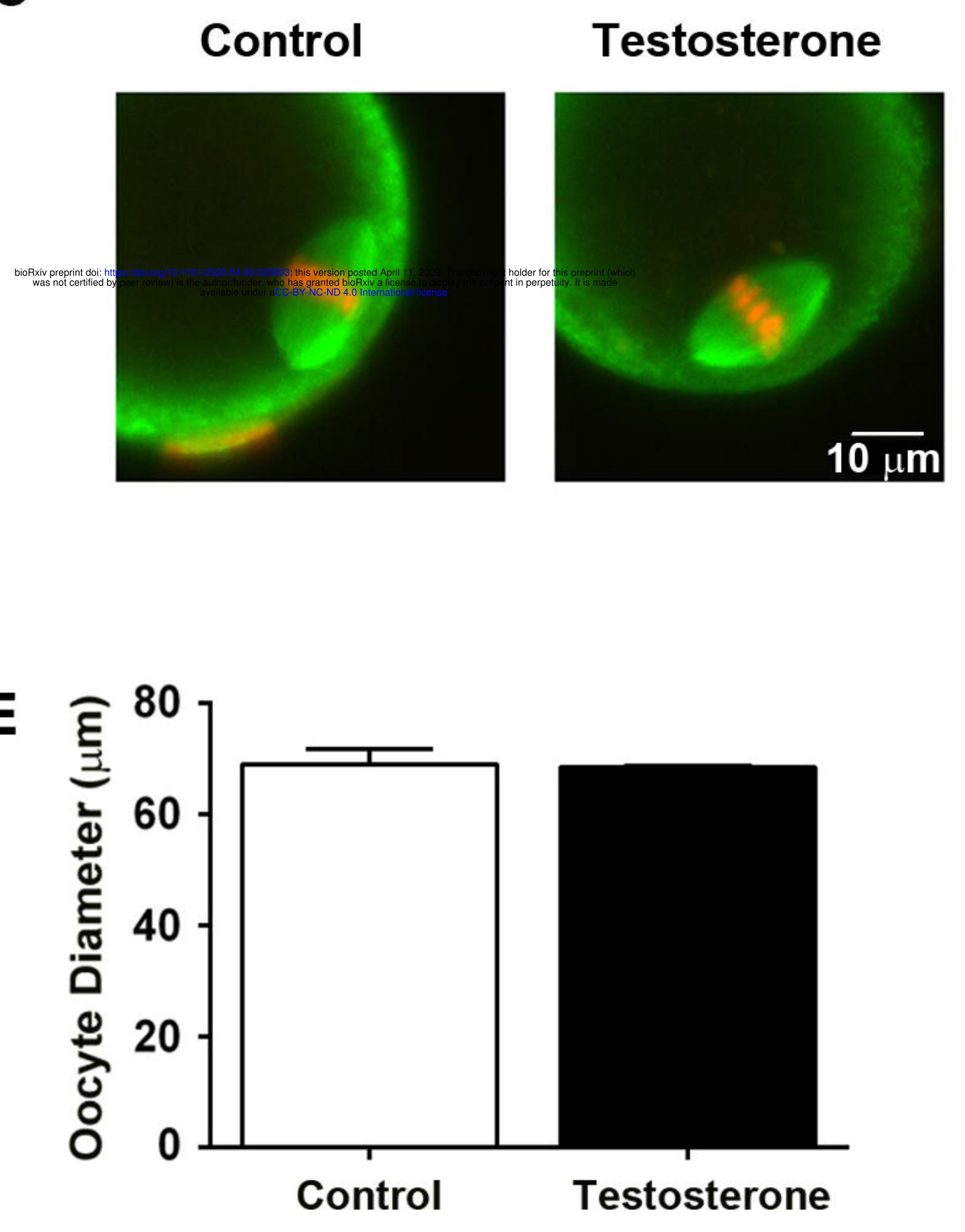

B

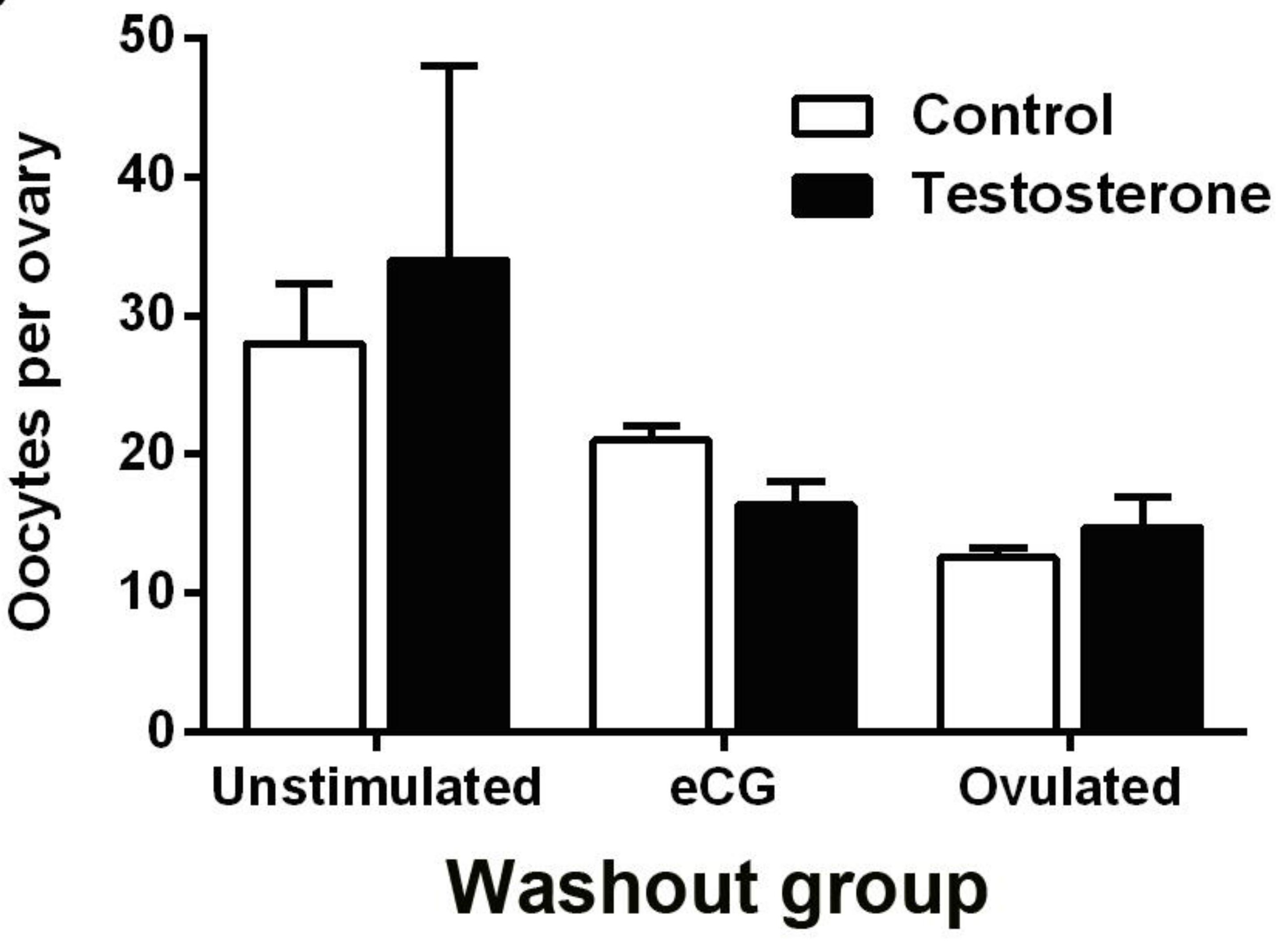

D

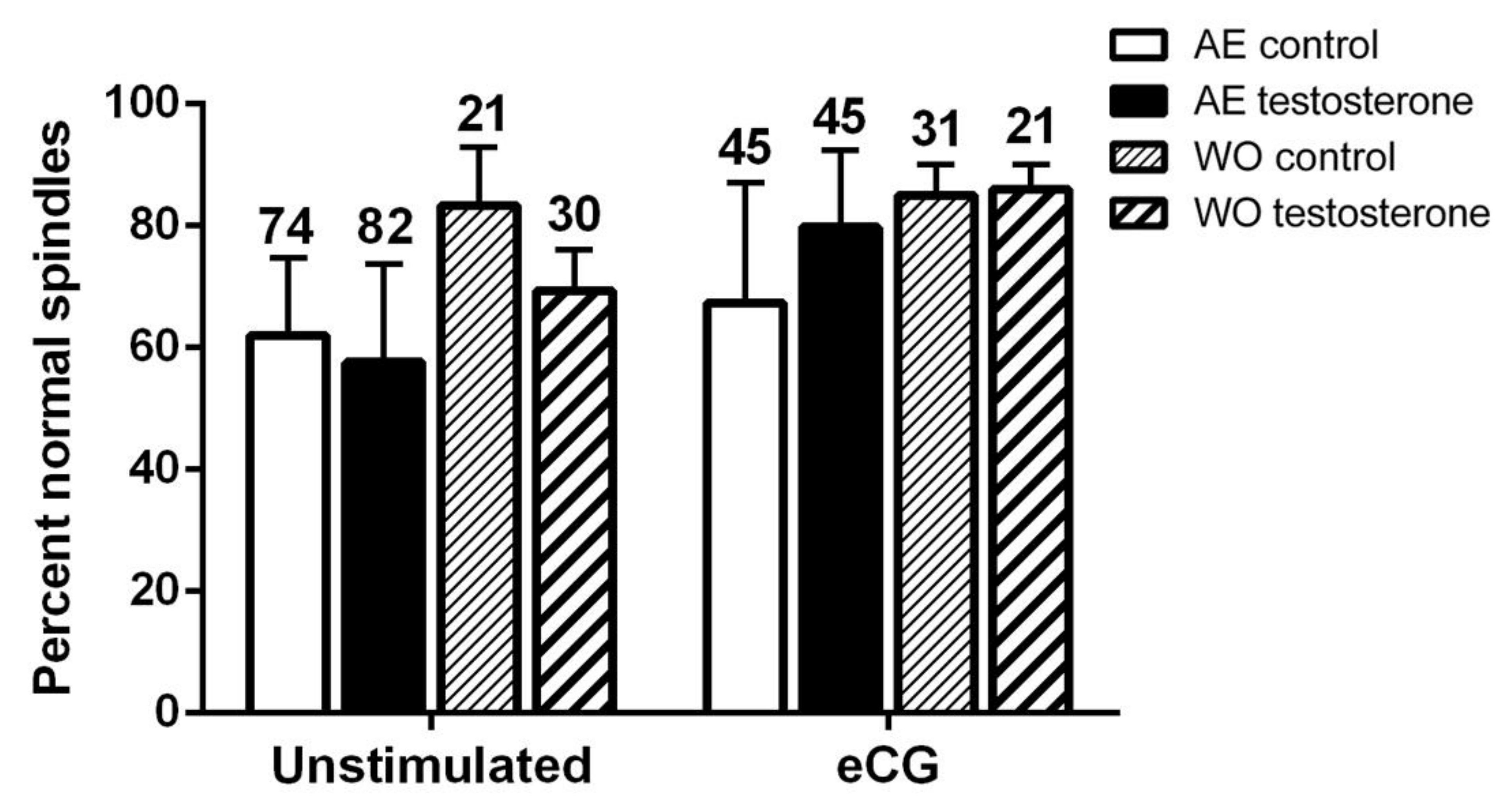


A
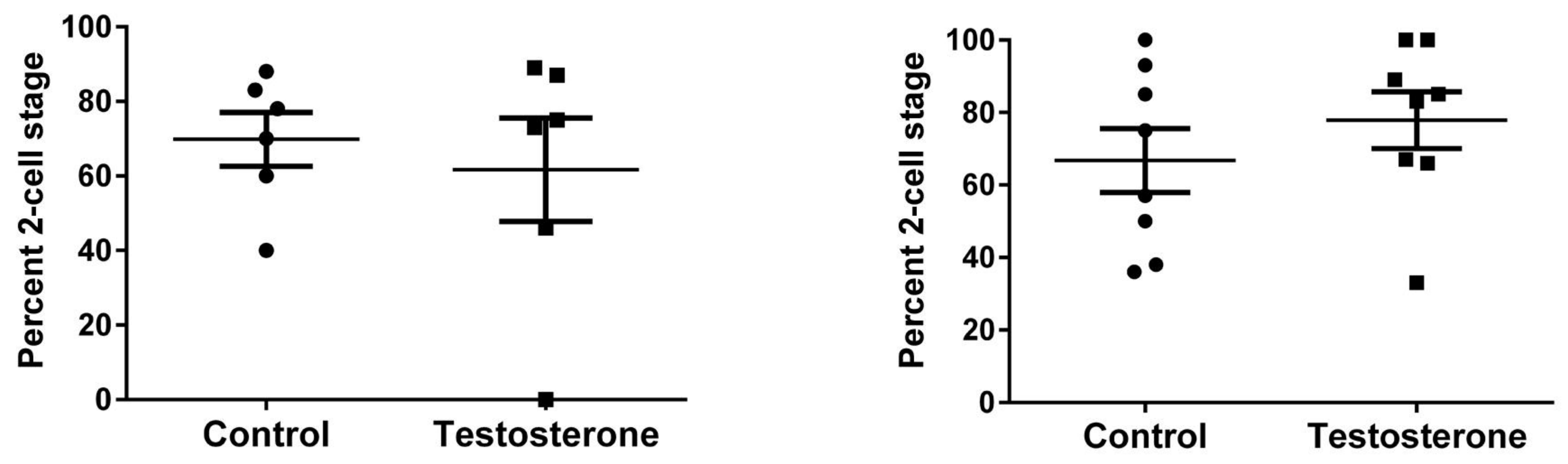

Active Exposure Group

Washout Group 